\title{
Discrete choice models and optimal two-part tariffs in the presence of externalities: optimal taxation of cars
}

\author{
by \\ Bruno De Borger (*) \\ University of Antwerp (UFSIA)
}

Belgium

\begin{abstract}
The purpose of this paper is to analyse optimal two-part tariffs in the presence of externalities within the framework of a model of discrete choice. The prototype application of the model is optimal taxation of car ownership and car use to correct for external costs. The externality we consider is allowed to cause feedback effects on demand and ownership shares and, therefore, on tax revenues. It is found that only the feedback effect of the externality on ownership shares is important in determining the optimal tax structure. When external costs differ between car types, it is shown that the role of fixed taxes crucially depends on the available variable tax instruments; various restrictions on variable tax instruments are analysed. We also study the implications of heterogeneity and distributive concerns for the optimal taxation of externalities via user and ownership taxes. We identify the specific role of the distribution of ownership and of conditional demands as well as the distributive impact of the externality itself.
\end{abstract}

JEL classification codes: H21, H23, R48

Key words: optimal taxation, two-part tariff, externalities, discrete choice

(*) Please send correspondence to Bruno De Borger, University of Antwerp (UFSIA), Prinsstraat 13, B-2000 Antwerp, Belgium. E-mail: bruno.deborger@ufsia.ac.be 


\section{Introduction}

The purpose of this paper is to study welfare-optimal two-part tariffs in the presence of externalities within the framework of a model of discrete choice. Although the analysis is quite relevant for pricing and tax policies towards other externality-generating durable goods, the prototype application for the model developed in this paper is the optimal taxation of cars. Recent discussions at the EUlevel suggest that the negative side-effects of car traffic (congestion, pollution, noise, accident risks) are a major concern in many European countries, and a variety of pricing and tax reform measures have been suggested that reflect external cost considerations $^{1}$. This naturally raises the issue of optimal two-part tariffs in the presence of externalities, since in most countries separate taxation of car ownership (through annual vehicle taxes) and car use (mainly via fuel taxes) implies that the tax structure is indeed reasonably well described as a two-part tariff. In this paper we analyse the role of fixed and variable taxes to cope with externalities under a variety of potential restrictions on the tax instruments, and allowing for both consumer heterogeneity and distributive concerns. We study the optimal tax problem within the framework of an explicit model of discrete choice. Not only do discrete choice models offer a natural framework for analysing the ownership and consumption decisions, it has also been shown that they are well suited for welfare economic applications (see, e.g., Small and Rosen (1981), Anderson, De Palma, and Thisse (1993)).

In the literature a few papers do exist that incorporate external cost considerations in the design of two-part tariffs. First, Littlechild (1975) studies the optimal two-part tariff in cases where extra consumers (and not extra units of consumption) generate 
positive externalities, such as in telecommunications. He shows that the optimal variable tax reflects marginal cost, and that the external effect is captured through appropriate adjustment of the fixed fee. Second, Glazer and Niskanen (1992) analyse the time-independent and the time-dependent components of parking fees as a twopart tariff. However, both papers use a totally different setting from the one in this paper. Moreover, they do not consider constraints on tax instruments, and they do not deal with the specific role of consumer heterogeneity and distributive concerns.

Somewhat surprisingly, the two-part tariff structure on vehicles has not been exploited in the large theoretical and empirical literature on optimal taxation of transport externalities. Relevant studies include, among many others, Glaister and Lewis (1978), Small (1983), Kraus (1989), Arnott et al (1993), De Borger et al (1997), Mayeres and Proost (1997), and Mayeres (2000). ${ }^{2}$ Although the existing work substantially varies both in terms of objective functions and in the level of detail (passengers versus freight, different modes, different car types, various fuels, etc.), all these models focus on optimal taxes per unit of consumption (typically per kilometre). As a consequence, they offer little advice on the potential role of fixed annual vehicle taxes to correct external cost differences between transport services. The vehicle ownership decision is usually not included in the model, and the few studies that do incorporate it do so in a rather ad hoc way. Even in these cases only user taxation is considered $^{3}$.

The implicit justification for not incorporating ownership taxation in optimal pricing models has probably been the first-best argument that correcting for externalities requires variable taxes that reflect marginal external costs, and that fixed ownership taxation has no explicit role to play. In an imperfect economic environment, however, this intuitive argument is not convincing. First, it is generally 
accepted that technical or political obstacles may prevent correcting the external costs of pollution or noise through an appropriate variable tax per car kilometre. Technically, optimal pricing would, among others, require measuring emissions and noise of various car types in different circumstances, and to charge each car at different points in time and space in function of the corresponding marginal external cost. Moreover, recent studies indicate that such pricing systems are not necessarily politically and socially acceptable (Lave (1994), Verhoef (1996)). In all cases where constraints exist on the optimal use of variable tax instruments, fixed taxes may be highly relevant. Not surprisingly, therefore, recent EU-policy documents (see, e.g., the White Paper (1999) on infrastructure charging) explicitly suggest fixed tax reforms as part of second-best policy packages, especially to cope with pollution (e.g., subsidise 'clean' cars). Second, in most countries taxes in the transport sector are not only aiming at internalising external costs, but governments also pursue budgetary objectives. As long as the latter matter, two-part tariffs are welfare improving and, even in the absence of external costs, variable taxes deviate from marginal cost if consumers are heterogeneous (see, for instance, $\mathrm{Ng}$ and Weisser (1974), Spence (1980)). Third, fixed taxes on car ownership may have a potentially important role when governments care about the distributive effect of both the externality and the corrective taxes. It is well known that such concerns are relevant in models of optimal indirect taxation (Sandmo (1975), Feldstein (1972), Sharkey and Sibley (1993)). The question is how distributive concerns affect the optimal trade-off between fixed and variable taxes when external costs, degrees of car ownership and car use differ across consumer types. Finally, transport externalities are known to generate feedback effects on demand and, as a consequence, they imply tax inducement effects (see, e.g., 
Mayeres and Proost (1997)). It is a priori unclear how these affect the optimal twopart tax structure.

To some extent, the model presented in this paper builds upon a previous paper (De Borger (2000)) that showed how to analyse two-part tax structures using a discrete choice framework. The current paper substantially extends the earlier work in various respects. First, the model incorporates fairly general consumer externalities and explicitly focuses on optimal two-part taxation to correct for external costs. The externality may cause feedback effects on demand and therefore on tax revenues. The implications of feedbacks for the tax structure are identified. Moreover, heterogeneity is introduced by considering different consumer types assumed to have different preferences, which imply differences in consumption patterns and in price sensitivities. Distributive concerns are incorporated as well, by applying different welfare weights to different consumer groups. Second, the model is extended to account for multiple two-part tariffs when external costs differ between substitutable goods (e.g., car types). Third, the role of fixed taxes to correct for external cost differences is explicitly analysed under various restrictions on the variable instruments to tax car use.

This paper has at least three obvious limitations. First, although it is well known that this specification is based on strong assumptions and imposes strong restrictions on substitution possibilities, we use the logit model of discrete choice throughout the paper. The main reason is analytical tractability. Unlike many other discrete choice models, the logit specification allows us to write both the ownership shares and the objective function of the welfare optimisation problem as simple closed-form expressions. This highly simplifies the technical analysis without leading to different insights ${ }^{4}$. Second, the paper assumes that the externalities related to car use are the 
only relevant externalities, and that taxes on car ownership and car use are the only instruments available to the government. This implies that all implications for the government run through the revenues from taxes on car ownership and car use. No other taxes are taken into account; restrictions on other tax instruments only enter the analysis through a nonzero shadow cost of public funds. Moreover, the analysis ignores possible pre-existing distortions elsewhere in the economy. For example, distortions on the labour market as well as those due to sub-optimal public transport fares are ignored (see, e.g., Parry and Bento (1999) on the welfare effects of preexisting tax distortions and the form of tax recycling in the case of congestion taxes). Third, the model considers the long-run impact of fixed taxes on car ownership and car use, but it does not explicitly analyse the dynamics of the adjustment.

The structure of the paper is as follows. In the next section we start out by analysing the welfare-optimal two-part tariff for the simplest possible case of a single good. It is shown that the optimal pricing structure not only depends on marginal external costs and on budgetary considerations, but also on the characteristics of the externality under investigation. In Section 3 the model is extended to multiple twopart tariffs on substitutable goods (e.g., multiple car types), and the implications of various restrictions on the variable tax instruments for the optimal pricing structure are analysed. Heterogeneity and distributive concerns are studied in Section 4. Given the available empirical evidence, the results indicate that it may be optimal to raise variable taxes on car use above marginal external cost and to correspondingly reduce fixed taxes. Finally, Section 5 concludes. 


\section{Optimal taxation of externalities in a logit model of discrete choice: the case of a single good}

In this section we consider the simplest case possible, viz. the case of a single good and homogenous consumers. To make the analysis more concrete the model is cast in terms of the optimal taxation of cars. Specifically, assume there are $n$ individuals consuming two goods. The first good $(\mathrm{x})$ is consumption of car kilometres, the second good $(\mathrm{z})$ is an aggregate consumption good treated as numeraire. Car use generates an external effect E, to be specified below. The government's problem is to determine the optimal taxes on car ownership and car use subject to a budgetary constraint ${ }^{5}$.

\subsection{Consumer behaviour}

Consumption of car kilometres involves both a discrete and a continuous choice. First consider the discrete decision whether or not to own a car. Define an index $i=1,2$ where $\mathrm{i}=1$ in the case of car ownership, and $\mathrm{i}=2$ otherwise. Indirect utility conditional on selecting alternative $\mathrm{i}\left(v_{i}\right)$ is specified as

$$
v_{i}=V_{i}+u_{i}
$$

where the $V_{i}$ are 'universal' indirect utility functions common to all individuals. The $u_{i}$ are individual-specific components that reflect idiosyncratic taste differences ${ }^{6}$. Universal utility $V_{1}$ associated with ownership is the solution to the consumer's problem of maximising a direct utility function $\mathrm{U}(\mathrm{x}, \mathrm{z}, \mathrm{E})$ subject to the relevant budgetary constraint. Denoting the variable price and the fixed fee that form the twopart tariff by $\mathrm{p}$ and $\mathrm{F}$, respectively, we therefore have ${ }^{7}$ : 


$$
V_{1}(p, y-F, E)=\operatorname{Max}_{x, z} U(x, z, E) \quad \text { s.t. } p x+F+z=y
$$

where $y$ is the consumer's income. In the alternative case of no ownership we simply have $V_{2}(y, E)=U(0, y, E)^{8}$. The level of $\mathrm{E}$ is treated as parametrically given by the individual. Moreover, he is assumed to ignore the nonzero but negligible impact of his behaviour on the externality level.

Variability in the $u_{i}$ implies that individual consumers do make different choices. Specifically, an individual will choose alternative i for which

$$
v_{i}=\operatorname{Max}_{i}\left(v_{1}, v_{2}\right)
$$

Assuming that the $u_{i}$ are i.i.d. and follow an extreme value distribution across alternatives and individuals, the fraction of the population owning a car (the ownership probability at the individual level) is given by

$$
\pi(p, y-F, E)=\frac{\exp \left(V_{1} / \mu\right)}{\exp \left(V_{1} / \mu\right)+\exp \left(V_{2} / \mu\right)}
$$

where $\mu$ is a scale parameter of the joint distribution of the $u_{i}$.

The demand for kilometres conditional on ownership is described by the conditional demand function $\mathrm{x}(\mathrm{p}, \mathrm{y}-\mathrm{F}, \mathrm{E})$; it can be derived from $V_{1}(p, y-F, E)$ by Roy's identity. Total demand in the population of $\mathrm{n}$ consumers is given by $\mathrm{X}$ where

$$
X=n \pi x=n * \pi(p, y-F, E) * x(p, y-F, E)
$$




\subsection{The nature of the externality}

We assume the external effect to be positively related to the total consumption of car kilometres in the population. In other words

$$
E=f(X)=f(n \pi x)=f[n * \pi(p, y-F, E) * x(p, y-F, E)]
$$

where $\frac{d f(X)}{d X}>0$. Note that this specification implies feedback effects (see, e.g., Mayeres and Proost (1997), De Borger (1997) and Munk (1999)) of the externality on demand and ownership. To see the implications of this, consider the impact of $\mathrm{p}$ and $\mathrm{F}$ on the externality level by totally differentiating (2) and rearranging the result. We obtain:

$$
\begin{aligned}
& \frac{d E}{d p}=\frac{\frac{\partial f(X)}{\partial X}\left[n\left(\pi \frac{\partial x}{\partial p}+x \frac{\partial \pi}{\partial p}\right)\right]}{1-\eta} \\
& \frac{d E}{d F}=\frac{\frac{\partial f(X)}{\partial X}\left[n\left(\pi \frac{\partial x}{\partial F}+x \frac{\partial \pi}{\partial F}\right)\right]}{1-\eta}
\end{aligned}
$$

where $\quad \quad \quad=\frac{\partial f(X)}{\partial X}\left[n\left(\pi \frac{\partial x}{\partial E}+x \frac{\partial \pi}{\partial E}\right)\right]$

is the feedback term. If external costs reduce ownership shares or conditional demands, $\eta$ is negative and the feedback weakens the impact of price changes on the externality. For example, an increase in the variable price $p$ directly raises the 
externality level, as measured by the numerator of (3). However, the induced increase in $\mathrm{E}$ affects conditional demand and the ownership share. The overall effect is therefore only a fraction $\frac{1}{1-\eta}$ of the direct impact.

Clearly, not all types of externalities generate feedback in demand. Congestion and accident risks probably do, especially in the long-run, because they are likely to affect the conditional demand for car use as well as the desirability of owning a car. Pollution, on the other hand, does affect consumer welfare, but it probably does not have any impact on car ownership decisions and on the demand for kilometres. If this is the case and pollution were the only relevant externality, $\eta$ would be zero.

\subsection{The optimal two-part tariff}

Assume the policy-maker is interested in designing an optimal two-part tariff on good x subject to a budgetary restriction. In a discrete choice framework, McFadden (1981) and Ben-Akiva and Lerman (1985) have suggested using the expected value of maximum utility across alternatives as a measure of welfare associated with the available options. For the logit model this implies that the government's problem can be formulated as follows (see Anderson, de Palma and Thisse (1993))

$$
\begin{aligned}
& \underset{p, F}{\operatorname{Max}} n \mu \ln \left\{\exp \left(\frac{V_{1}(p, y-F, E)}{\mu}\right)+\exp \left(\frac{V_{2}(y, E)}{\mu}\right)\right\} \\
& \text { subject to } \quad n \pi[(p-c) x+F] \geq G,
\end{aligned}
$$


where $\mathrm{G}$ is required government revenue, and $\mathrm{c}$ is the marginal production cost of $\mathrm{x}$. Alternatively, (p-c) corresponds to the variable tax per unit.

We normalise $n=1$ throughout the remainder of this section. Assuming the restriction is binding, the first-order conditions with respect to $\mathrm{p}$ and $\mathrm{F}$ can be written $\operatorname{as}^{9}$ (see Appendix 1 for details):

$$
\begin{aligned}
& (p-c-\theta)\left(\pi \frac{\partial x}{\partial p}+x \frac{\partial \pi}{\partial p}\right)+F \frac{\partial \pi}{\partial p}=\frac{\pi x}{\lambda}\left(\frac{\partial V_{1}}{\partial y}-\lambda\right) \\
& (p-c-\theta)\left(\pi \frac{\partial x}{\partial F}+x \frac{\partial \pi}{\partial F}\right)+F \frac{\partial \pi}{\partial F}=\frac{\pi}{\lambda}\left(\frac{\partial V_{1}}{\partial y}-\lambda\right)
\end{aligned}
$$

where $\lambda$ is the Lagrange multiplier associated with the budget restriction, and

$$
\theta=-\frac{\partial f(X)}{\partial X} \frac{1}{1-\eta} \frac{1}{\lambda}\left[\pi \frac{\partial V_{1}}{\partial E}+(1-\pi) \frac{\partial V_{2}}{\partial E}\right]-\frac{\partial f(X)}{\partial X} \frac{1}{1-\eta}\left[(p-c)\left(\pi \frac{\partial x}{\partial E}+x \frac{\partial \pi}{\partial E}\right)+F \frac{\partial \pi}{\partial E}\right]
$$

can be interpreted as the 'full' marginal external cost of an extra car kilometre, expressed in terms of government revenue. It consists of two components. The first term captures the welfare effects of an increase in X, taking account of the feedback and expressed in terms of government revenue. To see this, note that an increase in $\mathrm{X}$ induces an overall increase in the externality $\mathrm{E}$ equal to $\frac{\partial f(X)}{\partial X} \frac{1}{1-\eta}$. Moreover, simple algebra shows that the impact of the externality increase on the objective function of the welfare optimisation problem is given by $\left[\pi \frac{\partial V_{1}}{\partial E}+(1-\pi) \frac{\partial V_{2}}{\partial E}\right]$. This welfare effect is expressed in terms of government revenue through normalisation by the shadow price of the budget constraint $\lambda$. The second term of (8) captures the 
induced welfare cost associated with the loss of tax revenues. When the externality level rises this in turn reduces expected demand and thus tax revenues. Note that this second term will be zero whenever the feedback and tax inducement effects are zero.

The solution of the two-equation system (6)-(7) is given by (see Appendix 1)

$$
\begin{aligned}
& p-c-\theta=0 \\
& F=-\left(\frac{m_{1}-\lambda}{\lambda}\right) \frac{1}{(1-\pi) m_{1}}
\end{aligned}
$$

where we have written $m_{1}=\frac{\partial V_{1}}{\partial y}$ as the marginal utility of income for car owners to simplify notation; unless otherwise noted, it will be assumed to be constant. This solution implies a variable price equal to the full marginal external cost. The sign and magnitude of the fixed fee depends on the severity of the budget constraint. Suppose that $\lambda$ exceeds the marginal utility of income at the optimum $m_{1}$ so that $\frac{\lambda}{m_{1}}>1$. In other words, this is the case of a shadow price of public funds greater than one. Equation (10) then implies a positive fixed fee. However, if at the optimum variable tax revenues are so substantial that $m_{1}>\lambda$ then the budget restriction may allow for a fixed subsidy.

To elaborate on the precise role of the feedback and tax inducement effects, it is instructive to clearly separate out their impact in the definition of the full marginal cost. To do so, define the direct (i.e., ignoring feedback and tax inducement effects) marginal external cost $m e c^{d}$ as 


$$
m e c^{d}=-\frac{\partial f(X)}{\partial X} \frac{1}{\lambda}\left[\pi \frac{\partial V_{1}}{\partial E}+(1-\pi) \frac{\partial V_{2}}{\partial E}\right]
$$

Using (8), (9) and (11), we then have

$$
p-c-\frac{1}{1-\eta} m e c^{d}+\frac{\partial f(X)}{\partial X} \frac{1}{1-\eta}\left[(p-c)\left(\pi \frac{\partial x}{\partial E}+x \frac{\partial \pi}{\partial E}\right)+F \frac{\partial \pi}{\partial E}\right]=0
$$

Multiplying all terms by $1-\eta$, using the definition of $\eta$ (see (5)) and rearranging, we obtain

$$
p-c-m e c^{d}=-F \frac{\partial f(X)}{\partial X} \frac{\partial \pi}{\partial E}
$$

Finally, note that differentiation of (1) implies

$$
\frac{\partial \pi}{\partial E}=\pi(1-\pi)\left(\frac{\partial V_{1}}{\partial E}-\frac{\partial V_{2}}{\partial E}\right)
$$

Substituting this result together with (10) into (12) yields

$$
p-c=m e c^{d}+\frac{\partial f(X)}{\partial X} \frac{\pi}{m_{1}}\left(\frac{m_{1}-\lambda}{\lambda}\right)\left(\frac{\partial V_{1}}{\partial E}-\frac{\partial V_{2}}{\partial E}\right)
$$

The results, summarised by (12) and (14), show that the feedback effect does matter for the tax structure. Interestingly, only the feedback on the ownership probability matters. If the externality does not affect the ownership share $\left(\frac{\partial \pi}{\partial E}=0\right)$, the optimal variable tax equals the direct marginal external cost (see (12)), even if there are feedback and tax inducement effects associated with conditional demand $x^{10}$. If 
the externality makes car ownership less attractive then, assuming that the shadow cost of government funds at the optimum exceeds one so that $\mathrm{F}>0$, the variable tax is larger than the direct marginal external cost. The intuition is that under those circumstances the externality reduces tax revenues out of fixed taxes. This loss in tax revenues is 'compensated' by charging a variable tax that exceeds the direct marginal external cost.

The implication is that the variable tax rule depends on the type of externality considered or, more generally, on the composition of the overall external cost. For example, suppose that pollution is the only externality generated by car traffic and that car owners and non-owners are equally affected by pollution in the sense that

$$
\frac{\partial V_{1}}{\partial E}=\frac{\partial V_{2}}{\partial E}
$$

In this case, the externality does not affect the ownership share, and (12) and (14) indicate that the optimal variable tax equals the direct marginal external cost. Alternatively, assume congestion is the only relevant externality and that car owners suffer more from congestion than non-owners. Then (14) implies a variable tax exceeding the direct marginal external cost. Finally, if both pollution and congestion matter, the deviation of the variable tax from the direct marginal external cost depends on the relative importance of the two externalities.

\section{Optimal two-part taxes in the presence of externalities: multiple goods and restrictions on tax variable instruments}

In this section we consider multiple two-part tariffs on substitutable goods which generate different external costs. More importantly, we analyse the role of fixed taxes when there are restrictions on the use of variable tax instruments. The focus of the 
model is on optimal taxation of different types of cars that generate different marginal external costs ${ }^{11}$. For example, it is well known that gasoline and diesel imply substantial differences in emissions of various pollutants (see, Mayeres, Ochelen and Proost (1996)). Of course, since the model focuses on optimal taxes per kilometre, in this case differences in fuel efficiency should be taken into account when interpreting the results. Alternatively, marginal external costs may differ due to differences in the built-in emission technology (e.g., catalytic converter, direct injection, etc.) or in terms of other externality reducing characteristics (air bags, etc. $)^{12}$.

\subsection{No pricing restrictions}

As a benchmark, we first consider the case of perfect pricing instruments. Since nothing is gained by considering more, we limit the analysis to the case of two car types. Extending the analysis of the previous section is straightforward. Consumers have a choice between two car types ( $\mathrm{i}=1$ or 2 , respectively); alternatively, they may prefer not to own a car $(i=3)^{13}$. Fixed taxes on the two types of car are denoted by $F_{1}$ and $F_{2}$, respectively. Similarly, variable prices are $p_{1}$ and $p_{2}$, and variable production costs are $c_{1}, c_{2}$. The relevant market shares are

$$
\pi_{i}\left(p_{1}, p_{2}, F_{1}, F_{2}, y, E\right)=\frac{e^{\frac{V_{i}}{\mu}}}{e^{\frac{V_{1}}{\mu}}+e^{\frac{V_{2}}{\mu}}+e^{\frac{V_{3}}{\mu}}}
$$

where $V_{i}=V_{i}\left(p_{i}, y-F_{i}, E\right)$ and $V_{3}=V_{3}(y, E)$ are the respective common conditional indirect utilities $(\mathrm{i}=1,2)$. Conditional demands are given by $x_{i}\left(p_{i}, y-F_{i}, E\right), \mathrm{i}=1,2$. 
Finally, the externality $\mathrm{E}$ is the result of the demand for car kilometres by users of the two car types in the population

$$
E=f\left(X_{1}, X_{2}\right), X_{1}=n \pi_{1} x_{1}, X_{2}=n \pi_{2} x_{2}
$$

It is no surprise that the solution to the optimal tax problem is characterised by the following pricing rules (see Appendix 2):

$$
\begin{aligned}
& p_{1}-c_{1}-\theta_{1}=0 \\
& p_{2}-c_{2}-\theta_{2}=0 \\
& F_{1}=-\left(\frac{m_{1}-\lambda}{\lambda}\right) \frac{1}{\left(1-\pi_{1}-\pi_{2}\right) m_{1}} \\
& F_{2}=-\left(\frac{m_{2}-\lambda}{\lambda}\right) \frac{1}{\left(1-\pi_{1}-\pi_{2}\right) m_{2}}
\end{aligned}
$$

where the $m_{i}=\frac{\partial V_{i}}{\partial y}$ are the marginal utilities of income conditional on the choice of car type i. The parameters $\theta_{i}$ and $\eta$ have the same interpretation as before, but they are slightly redefined to account for the existence of multiple car types.

The results are as expected. First, variable taxes on both goods equal the full marginal external cost. Second, variable taxes in general differ from the appropriate direct marginal external costs unless ownership shares are unaffected by externalities. One easily shows that

$$
\begin{aligned}
& p_{1}-c_{1}=m e c_{1}^{d}+\frac{\partial f\left(X_{1}, X_{2}\right)}{\partial X_{1}}\left(\frac{m_{1}-\lambda}{\lambda}\right) \frac{1}{m_{1}\left(1-\pi_{1}-\pi_{2}\right)}\left(\frac{\partial \pi_{1}}{\partial E}+\frac{\partial \pi_{2}}{\partial E}\right) \\
& p_{2}-c_{2}=m e c_{2}^{d}+\frac{\partial f\left(X_{1}, X_{2}\right)}{\partial X_{2}}\left(\frac{m_{2}-\lambda}{\lambda}\right) \frac{1}{m_{2}\left(1-\pi_{1}-\pi_{2}\right)}\left(\frac{\partial \pi_{1}}{\partial E}+\frac{\partial \pi_{2}}{\partial E}\right)
\end{aligned}
$$

where 


$$
m e c_{i}^{d}=-\frac{\partial f\left(X_{1}, X_{2}\right)}{\partial X_{i}} \frac{1}{\lambda}\left[\pi_{1} \frac{\partial V_{1}}{\partial E}+\pi_{2} \frac{\partial V_{2}}{\partial E}+\left(1-\pi_{1}-\pi_{2}\right) \frac{\partial V_{3}}{\partial E}\right]
$$

is the direct marginal welfare cost of an increase in demand for kilometres by car type i, expressed in terms of government revenue. Third, if the conditional marginal utilities are equal $\left(m_{1}=m_{2}\right)$, there is no reason to introduce different fixed taxes on the different car types; external cost differences are captured by variable taxes only. If conditional marginal utilities of income do differ depending on the consumer's choice of car type, then the larger marginal utility the smaller the optimal fixed tax on the corresponding car type.

The above result has a straightforward implication for the optimal taxation of durable goods with different marginal external costs. Consider car taxes in Europe. It has been suggested that even on a per kilometre basis, diesel is more polluting than gasoline (Mayeres, Ochelen, Proost (1996), Mayeres (2000)). If this is true, the optimal tax rules of this subsection would suggest that diesel should be subject to a higher variable tax per kilometre. Therefore, given the differences in fuel use per kilometre between both fuel types, diesel should definitely be subject to a higher tax per litre. On the other hand, the results also imply that diesel and gasoline cars with similar characteristics (except for fuel used) should be subject to approximately the same fixed tax. This would imply a drastic revision of the current tax systems. Although there is a large variability in tax treatment of diesel and gasoline across European countries, all countries impose a higher per litre tax on gasoline (ACEA (various issues)). This implies, given differences in average fuel consumption, a lower tax per kilometre on diesel. At the same time, most countries charge higher annual fixed taxes on diesel cars. Of course, fuel taxes in Europe serve many other purposes, but more emphasis on external cost considerations would be highly desirable. 
Fortunately, there are some recent indications that tax systems in at least some countries move in the right direction. For example, in the UK differences in fuel tax between diesel and (unleaded) gasoline are reasonably small, and flat ownership taxes are applied. In the early nineties, Sweden imposed a surcharge on diesel fuel, although the overall tax per litre remains lower on diesel than on gasoline (ACEA).

\subsection{Restrictions on tax instruments I: Optimal fixed taxes given sub-optimal variable} prices

In this subsection we consider, conditional on given and sub-optimal variable taxes, how fixed taxes have to be adjusted in order to correct for differences in external costs. Among other cases, the analysis is relevant when the government uses fuel taxes as the main variable tax. For example, for technical or political reasons it may be unable to implement the optimal tax differentiation between use of diesel and gasoline in function of external cost differences. Alternatively, apart from exogenous differences in fuel consumption, it will be unable to optimally correct for differences in external costs that are unrelated to fuel type (e.g., because of technological differences such as in terms of fuel injection, catalytic converter, air bags, etc.).

It is shown in Appendix 3 that the solution to the problem

$$
\begin{aligned}
& \underset{F_{1}, F_{2}}{\operatorname{Max}} \mu \ln \left\{\exp \left(\frac{V_{1}\left(p_{1}, y-F_{1}, E\right)}{\mu}\right)+\exp \left(\frac{V_{2}\left(p_{2}, y-F_{2}, E\right)}{\mu}\right)+\exp \left(\frac{V_{3}(y, E)}{\mu}\right)\right\} \\
& \text { subject to }\left\{\left[\left(p_{1}-c_{1}\right) x_{1}+F_{1}\right] \pi_{1}+\left[\left(p_{2}-c_{2}\right) x_{2}+F_{2}\right] \pi_{2}\right\} \geq G
\end{aligned}
$$

is given by 


$$
\begin{aligned}
& F_{1}=\frac{-\left(\frac{m-\lambda}{\lambda}\right)+\left(p_{1}-c_{1}-\theta_{1}\right)\left[\left(1-\pi_{2}\right) \frac{\partial x_{1}}{\partial F_{1}}-x_{1} m\left(1-\pi_{1}-\pi_{2}\right)\right]+\left(p_{2}-c_{2}-\theta_{2}\right)\left(\pi_{2} \frac{\partial x_{2}}{\partial F_{2}}\right)}{m\left(1-\pi_{1}-\pi_{2}\right)} \\
& F_{2}=\frac{-\left(\frac{m-\lambda}{\lambda}\right)+\left(p_{1}-c_{1}-\theta_{1}\right)\left(\pi_{1} \frac{\partial x_{1}}{\partial F_{1}}\right)+\left(p_{2}-c_{2}-\theta_{2}\right)\left[\left(1-\pi_{1}\right) \frac{\partial x_{2}}{\partial F_{2}}-x_{2} m\left(1-\pi_{1}-\pi_{2}\right)\right]}{m\left(1-\pi_{1}-\pi_{2}\right)}
\end{aligned}
$$

where we have assumed for simplicity that the marginal utilities of income are independent of the choice of car type, i.e., $m_{1}=m_{2}=m$. To ease the interpretation, it is instructive to subtract (24) from (23) and to rearrange the result so as to obtain

$$
F_{1}-F_{2}=\left(p_{1}-c_{1}-\theta_{1}\right)\left[\frac{1}{m}\left(\frac{\partial x_{1}}{\partial F_{1}}-m x_{1}\right)\right]-\left(p_{2}-c_{2}-\theta_{2}\right)\left[\frac{1}{m}\left(\frac{\partial x_{2}}{\partial F_{2}}-m x_{2}\right)\right]
$$

The terms between square brackets are negative as long as car kilometres are a normal good.

Of course, the exact form of the optimal tax expressions presented in this section is based on use of the logit specification. Specifically, appropriate differentiation of (17) implies that all price and cross-price effects of the ownership shares can be expressed in terms of the respective $\pi_{i}$ and the relevant marginal utilities of income. However, the qualitative implications of the tax rules do not depend on the specific discrete choice framework used. The main findings are easily summarised. First, they confirm our previous finding that, if variable taxes are optimally set (i.e., if $p_{i}-c_{i}-\theta_{i}=0$ for both i), then $F_{1}=F_{2}$. Second, they suggest that the fixed tax levels $F_{i}$ do depend on the car ownership shares $\pi_{i}$ at the optimum 
(see (23) and (24)), but that the absolute tax difference $F_{1}-F_{2}$ (see (25)) is independent of the relative ownership shares of the two car types. In other words, higher ownership shares have revenue effects that affect both individual fixed fees, but they leave the difference unaffected. Third, if variable prices do not reflect marginal social costs, the simple and intuitive conclusion is that the goods that generate lower external costs should not necessarily enjoy lower fixed taxes ${ }^{14}$. Whether or not this will be the case depends on the structure of user taxes relative to external costs, on conditional demands for the different car types at the optimal tax configuration, and on the various price sensitivities.

To elaborate briefly on this last point, let us assume throughout that car type 1 incorporates cleaner technologies than type 2, so that $\theta_{1}<\theta_{2}$. Several cases can then be distinguished. First, assume that the use of the clean type of car is over-priced and that kilometres produced by the dirty technology are insufficiently taxed, so that $p_{1}-c_{1}-\theta_{1}>0$ and $p_{2}-c_{2}-\theta_{2}<0$. Then (25) immediately implies that $F_{1}<F_{2}$. The intuition is obvious: variable prices excessively tax the clean technology; this is corrected by imposing a lower fixed tax. Second, consider the (less realistic) case where use of the clean technology is insufficiently taxed by the variable price system, whereas the dirty technology is excessively taxed so that $p_{1}-c_{1}-\theta_{1}<0, p_{2}-c_{2}-\theta_{2}>0$. This yields $F_{1}>F_{2}$. The clean technology is subject to a higher fixed tax, because the variable user tax does not fully cover the (relatively small) marginal external cost.

A third possibility is that both the dirty and the clean technology are priced at more than their marginal social costs (i.e., $p_{1}-c_{1}-\theta_{1}>0, p_{2}-c_{2}-\theta_{2}>0$ ). In that case, (25) implies that the clean technology will be subject to a smaller fixed tax only 
if a combination of conditions holds. The likelihood that $F_{1}<F_{2}$ positively depends (i) on the degree to which the variable tax system over-prices the clean technology, (ii) on conditional demand for the clean technology at the optimum, and (iii) on the sensitivity of conditional demand for kilometres by clean cars with respect to the corresponding fixed fee. The latter two conditions are related to the revenue effects of the tax system. If demand is very sensitive to the fixed tax this gives an incentive to keep $F_{1}$ low because raising it would substantially reduce demand and therefore variable tax revenues. Similarly, if $x_{1}$ is large the variable tax on this good generates substantial revenues, allowing the corresponding fixed tax to be reduced. Note that, by the same argument, the likelihood that $F_{1}<F_{2}$ negatively depends on (i) the degree of overpricing of the dirty technology, (ii) on the conditional demand for the dirty technology, and (iii) on the sensitivity of demand for use of cars with the dirty technology with respect to changes in $F_{2}$. Again, the latter two conditions are related to revenue effects.

Finally, if both variable taxes are insufficient to cover the relevant marginal external costs $\left(p_{1}-c_{1}-\theta_{1}<0, p_{2}-c_{2}-\theta_{2}<0\right)$, similar arguments suggest that $F_{1}<F_{2}$ is more likely if, first, the clean technology is priced much closer to marginal social cost than the dirty technology. Second, if conditional demand for kilometres by the clean technology is small and if this demand is not very sensitive for fixed tax changes. Third, if there is a high and price sensitive conditional demand for the dirty technology.

For an example of the implications of the above results, return to the taxation of diesel versus gasoline. As previously suggested, most countries apply lower taxes per litre on diesel than on gasoline. Averaging over peak and off-peak periods, the 
current variable tax expressed on a per kilometre basis under-prices diesel much more severely than gasoline (for Belgian evidence see De Borger et al. (1997), Mayeres (2000)). Taking the variable tax structure as exogenous and conditional on the level of variable taxes relative to external costs, the previous analysis then indicates that higher fixed taxes on diesel cars may be an appropriate response. Especially countries that strongly under-tax diesel fuel (e.g., Belgium; the Netherlands, France, Italy, etc.) may argue in favour of substantially higher ownership taxes on diesel cars. Of course, this assumes that for some reason fuel taxes cannot be directly adjusted to reflect external cost differences, which is probably an untenable assumption.

\subsection{Restrictions on tax instruments II: the impossibility of variable tax differentiation}

In this subsection we assume that the government can use both fixed and variable taxes, but that it cannot discriminate the variable price between car types. This is relevant if the government is using fuel taxes in combination with fixed taxes on the two car types, and externality differences between car types are unrelated to fuel consumption. This is the case for many recent technological advances and for a number of safety features. Indeed, for a given fuel type external costs may differ between cars because of different emission technologies (e.g., catalytic converter incorporated or not, direct injection or not, etc.) or between cars with different safety attributes (e.g., airbag or not). In all such cases even an 'optimal' fuel tax will be unable to differentiate the variable tax per kilometre between cars with different pollution and safety characteristics.

The problem is to 


$$
\begin{aligned}
& \underset{p, F_{1}, F_{2}}{\operatorname{Max}} \mu \ln \left\{\exp \left(\frac{V_{1}\left(p, y-F_{1}, E\right)}{\mu}\right)+\exp \left(\frac{V_{2}\left(p, y-F_{2}, E\right)}{\mu}\right)+\exp \left(\frac{V_{3}(y, E)}{\mu}\right)\right\} \\
& \text { subject to }\left\{\left[\left(p-c_{1}\right) x_{1}+F_{1}\right] \pi_{1}+\left[\left(p-c_{2}\right) x_{2}+F_{2}\right] \pi_{2}\right\} \geq G
\end{aligned}
$$

The solution is described by the pricing rules (see Appendix 4)

$$
p-s_{1}\left(c_{1}+\theta_{1}\right)-s_{2}\left(c_{2}+\theta_{2}\right)=0
$$

$$
\begin{aligned}
F_{1}= & -\left(\frac{m-\lambda}{\lambda}\right) \frac{1}{\left(1-\pi_{1}-\pi_{2}\right) m} \\
& +\left[\frac{c_{1}+\theta_{1}-c_{2}-\theta_{2}}{\left(1-\pi_{1}-\pi_{2}\right) m}\right]\left\{s_{1}\left(\pi_{2} \frac{\partial x_{2}}{\partial F_{2}}\right)-s_{2}\left[\left(1-\pi_{2}\right) \frac{\partial x_{1}}{\partial F_{1}}-x_{1} m\left(1-\pi_{1}-\pi_{2}\right)\right]\right\}
\end{aligned}
$$$$
F_{2}=-\left(\frac{m-\lambda}{\lambda}\right) \frac{1}{\left(1-\pi_{1}-\pi_{2}\right) m}
$$$$
+\left[\frac{c_{2}+\theta_{2}-c_{1}-\theta_{1}}{\left(1-\pi_{1}-\pi_{2}\right) m}\right]\left\{s_{2}\left(\pi_{1} \frac{\partial x_{1}}{\partial F_{1}}\right)-s_{1}\left[\left(1-\pi_{1}\right) \frac{\partial x_{2}}{\partial F_{2}}-x_{2} m\left(1-\pi_{1}-\pi_{2}\right)\right]\right\}
$$

where $\quad s_{i}=\frac{\pi_{i} \frac{\partial \hat{x}_{i}}{\partial p}}{\pi_{1} \frac{\partial \hat{x}_{1}}{\partial p}+\pi_{2} \frac{\partial \hat{x}_{2}}{\partial p}}, \mathrm{i}=1,2$

and the $\frac{\partial \hat{x}_{i}}{\partial p}=\frac{\partial x_{i}}{\partial p}-x_{i} \frac{\partial x_{i}}{\partial F_{i}}$ are compensated price effects of conditional demand.

Interpretation is as follows. The variable price is a weighted average of the marginal social costs. The weights $s_{i}$ reflect the relative ownership shares and the relative price sensitivities of conditional demands for the two car types. To minimise distortions, the common variable price will be closer to the marginal social cost of a 
given car type the larger the ownership share and the larger the price sensitivity of conditional demand.

To characterise the fixed tax rules, first note that we find the same pricing rules as in the absence of pricing restrictions if the marginal social costs $\left(c_{i}+\theta_{i}\right)$ are the same for the two car types. In that case, car use is taxed at marginal external cost for both car types, and the fixed tax rules reduce to (21)-(22). Second, simple algebra shows that the relative size of the fixed taxes is uniquely determined by the relative marginal social costs. To see this, subtract (29) from (28) and rearrange to obtain

$$
F_{1}-F_{2}=\left[\frac{c_{1}+\theta_{1}-c_{2}-\theta_{2}}{m}\right]\left[s_{1}\left(m x_{2}-\frac{\partial x_{2}}{\partial F_{2}}\right)+s_{2}\left(m x_{1}-\frac{\partial x_{1}}{\partial F_{1}}\right)\right]
$$

Since the last term between square brackets is positive (making abstraction of inferior car types), it follows that the car type $\mathrm{i}$ with the largest marginal social cost $c_{i}-\theta_{i}$ will be subject to the highest fixed tax. The absolute tax difference depends on price sensitivities and relative conditional demands.

To understand the interaction between variable and fixed taxes it may be instructive to consider some special cases. Assume $c_{1}+\theta_{1}<c_{2}+\theta_{2}$. This (see (31)) immediately implies that $F_{1}<F_{2}$. Now take the extreme case where $s_{1}$ is very small, i.e., the clean technology is either not observed or extremely price inelastic. Then (27) implies that the common variable price approaches marginal social cost of the dirty technology, $p=c_{2}+\theta_{2}$. Moreover, (28) and (29) indicate that both fixed taxes are 'structurally' lower than in the absence of pricing restrictions. The intuition is obvious. Setting the variable price at the marginal social cost of the dirty technology implies that the use of the clean car is 'overpriced'. This is corrected by charging 
lower fixed taxes, where of course the lowest tax applies to the clean technology. Alternatively, let $s_{2}=0$. Then the variable price per kilometre reflects the marginal social cost of the clean technology, $p=c_{1}+\theta_{1}$. Under these conditions, (28) and (29) yield fixed taxes that are structurally above those at the first-best. Setting the variable price at the marginal social cost of the clean technology implies that the use of the dirty technology is under-priced. This results in higher fixed taxes where, again, the lowest tax applies to the clean technology.

In sum, the variable price will be closer to the marginal social cost of the dirty technology the larger the ownership share of the dirty car type, and the larger the corresponding conditional demand price sensitivity. However, the closer the variable price to the marginal social cost of the dirty technology, the lower the fixed taxes, where the clean technology consistently enjoys the lowest tax. Note that these findings contrast with those of the previous subsection, where the clean technology did not necessarily enjoy the lower fixed tax. In this subsection the availability of the common variable price as an extra policy instrument does yield relative fixed taxes that are uniquely determined by relative marginal social costs. However, the different results can easily be reconciled. Indeed, the variable pricing rule implies that the price is situated between the marginal social costs of the clean and dirty technologies, so that the externality generated by the clean technology is to some extent over-priced, whereas the dirty technology is under-priced. Assuming that the first car type is the clean alternative we found in the previous subsection that these conditions indeed imply $F_{1}<F_{2} \cdot{ }^{15}$

The results of this subsection are especially relevant if the government can implement an optimal fuel tax but is also interested in correcting for differences in externalities that are unrelated to fuel use. In that case it is optimal to apply fixed tax 
reductions to cars incorporating externality-reducing technologies such as airbags, catalytic converters, direct injection, etc. These technologies may actually even be subsidised (i.e., $F_{1}<0$ ) if the demand for kilometres by clean cars is large and not very price-sensitive (see (28)). Although this is not necessarily an indication of optimal behaviour (since fuel taxes are probably not optimal, see above), a number of countries (e.g., Germany, Italy, Greece, etc. See ACEA) have introduced measures that point in the right direction. Examples include a reduction of ownership taxes on 'clean' diesel cars, tax reductions on cars fitted with a catalytic converter, etc.

\section{The role of consumer heterogeneity and distributive concerns}

In this section we look at heterogeneity and distributive issues. Although extension to multiple goods is conceptually easy, to keep the analysis transparent we return to the case of a single good. In that case we can use the model analysed in De Borger (2000) and extend it to take account of externalities. We first derive the optimal tax results, and then discuss in detail the role of both heterogeneity and distributive concerns. Finally, some empirical implications are briefly pointed out.

\subsection{Derivation of the optimal tax rules}

Let there be $\mathrm{H}$ consumer types, each type $\mathrm{h}$ consisting of $\mathrm{n}^{\mathrm{h}}$ people. In view of the discussion in the previous section, the problem of determining the welfare-optimal twopart tariff can be formulated as follows: 


$$
\begin{aligned}
& \underset{p, F}{\operatorname{Max}} \sum_{h} \beta^{h} n^{h} \mu^{h}\left\{\ln \left[\exp \left(\frac{V_{1}^{h}\left(p, y^{h}-F, E\right)}{\mu^{h}}\right)+\exp \left(\frac{V_{2}^{h}\left(y^{h}, E\right)}{\mu^{h}}\right)\right]\right\} \\
& \text { s.t. } \quad(p-c)\left(\sum_{h} n^{h} \pi^{h} x^{h}\right)+F\left(\sum_{h} n^{h} \pi^{h}\right) \geq G
\end{aligned}
$$

where the $\beta^{h}$ are welfare weights. The externality E depends on aggregate consumption of $\operatorname{good} x$, i.e., $\mathrm{E}=\mathrm{f}(\mathrm{X})$ with $X=\sum_{h} n^{h} \pi^{h} x^{h}$.

The first-order conditions for $\mathrm{p}$ and $\mathrm{F}$ can be written as (also see Appendix 5):

$$
\begin{aligned}
& (p-c-\theta)\left[\sum_{h} n^{h}\left(\pi^{h} \frac{\partial \hat{x}^{h}}{\partial p}+x^{h} \frac{\partial \hat{\pi}^{h}}{\partial p}\right)\right]+F\left[\sum_{h} n^{h} \frac{\partial \hat{\pi}^{h}}{\partial p}\right]=\sum_{h} n^{h} \pi^{h} x^{h}\left(\alpha^{h}-1\right) \\
& (p-c-\theta)\left[\sum_{h} n^{h} \frac{\partial \hat{\pi}^{h}}{\partial p}\right]+F\left[\sum_{h} n^{h} \frac{1}{x^{h}} \frac{\partial \hat{\pi}^{h}}{\partial p}\right]=\sum_{h} n^{h} \pi^{h}\left(\alpha^{h}-1\right)
\end{aligned}
$$

where the $\hat{x}$ and $\hat{\pi}$ indicate compensated demand and probability effects of price changes (for definition and interpretation of compensated probability functions see, e.g., Small and Rosen (1981)). The full marginal external cost associated with a small increase in $\mathrm{X}$ is now defined as

$$
\begin{aligned}
\theta=-\frac{\partial f}{\partial X} \frac{1}{1-\eta} & \frac{1}{\lambda}\left\{\sum_{h} \beta^{h} n^{h}\left[\pi^{h} \frac{\partial V_{1}^{h}}{\partial E}+\left(1-\pi^{h}\right) \frac{\partial V_{2}^{h}}{\partial E}\right]\right\} \\
& -\frac{\partial f}{\partial X} \frac{1}{1-\eta}\left\{(p-c)\left[\sum_{h} n^{h}\left(\pi^{h} \frac{\partial x^{h}}{\partial E}+x^{h} \frac{\partial \pi^{h}}{\partial E}\right)\right]+F\left(\sum_{h} n^{h} \frac{\partial \pi^{h}}{\partial E}\right)\right\}
\end{aligned}
$$

Finally,

$$
\alpha^{h}=\frac{\beta^{h}}{\lambda} \frac{\partial V_{1}^{h}}{\partial y^{h}}+\frac{1}{\pi^{h}}\left[(p-c-\theta)\left(\pi^{h} \frac{\partial x^{h}}{\partial y^{h}}+x^{h} \frac{\partial \pi^{h}}{\partial y^{h}}\right)+F \frac{\partial \pi^{h}}{\partial y^{h}}\right]
$$


is the net marginal social utility of income (see Diamond (1975)) for owners of the good. It takes account of the existence of external costs and is expressed in terms of government revenue. The $\alpha^{h}$ 's capture three effects of an income increase to an individual of group $\mathrm{h}$. The first term reflects the social welfare impact of an income increase; it is expressed in terms of government revenue by dividing through by $\lambda$. Second, they capture the induced fixed and variable tax revenues of an income increase. Third, account is taken of the impact of income increases on external costs. An income increase affects the expected demand for the externality-generating good, which in turn affects the externality level. The welfare cost of this increase in externality $\mathrm{E}$ is measured by the full marginal social $\operatorname{cost} \theta$. Note that the tax revenue and externality effects are normalised by the ownership probability so that the $\alpha^{h}$ 's measure net marginal social utility for owners.

To focus on distributive issues it will be useful to introduce distributive characteristics (see, e.g., Feldstein (1972), Bös (1986), Sandmo (1975)). To clearly separate the distribution of car ownership and of conditional demands, we define distributive characteristics of ownership and demand as follows

$$
\begin{gathered}
\bar{\alpha}^{o}=\frac{\sum_{h} n^{h} \pi^{h} \alpha^{h}}{N} \\
\bar{\alpha}^{d}=\frac{\sum_{h} n^{h} \pi^{h} x^{h} \alpha^{h}}{X}
\end{gathered}
$$

Note that $\bar{\alpha}^{o}$ will be large if groups with high ownership probabilities are assigned high net marginal social utilities. Similarly, $\bar{\alpha}^{d}$ will be large if groups characterised by high expected demands receive large social valuations. Of course, both distributive characteristics are closely related. One easily shows 


$$
\bar{\alpha}^{d}=\bar{\alpha}^{o}+\frac{1}{X}\left[\sum_{h} n^{h} \pi^{h} \alpha^{h}\left(x^{h}-\frac{X}{N}\right)\right]
$$

In other words, the distributive characteristic of overall demand reflects both the social valuation of ownership differences and of differences in conditional demands between groups.

Substituting the distributive characteristics in the first-order conditions (32)

we obtain

$$
\begin{aligned}
& (p-c-\theta)\left[X_{p}\right]+F\left[\sum_{h} \rho^{h} x^{h}\right]=X\left(\bar{\alpha}^{d}-1\right) \\
& (p-c-\theta)\left[\sum_{h} \rho^{h} x^{h}\right]+F\left[\sum_{h} \rho^{h}\right]=N\left(\bar{\alpha}^{o}-1\right)
\end{aligned}
$$

where

$$
X_{p}=\left[\sum_{h} n^{h}\left(\pi^{h} \frac{\partial \hat{x}^{h}}{\partial p}+x^{h} \frac{\partial \hat{\pi}^{h}}{\partial p}\right)\right]<0
$$

is the price impact on total demand, and

$$
\rho^{h}=n^{h} \frac{1}{x^{h}} \frac{\partial \hat{\pi}^{h}}{\partial p}<0 .
$$

The solution be britten as

$$
\begin{aligned}
& p-c-\theta=\frac{1}{D}\left\{\left[X\left(\sum_{h} \rho^{h}\right)\right]\left[\bar{\alpha}^{d}\right]-\left[N\left(\sum_{h} \rho^{h} x^{h}\right)\right]\left[\bar{\alpha}^{o}\right]+B N\right\} \\
& F=-\frac{1}{D}\left\{\left[X\left(\sum_{h} \rho^{h} x^{h}\right)\right]\left[\bar{\alpha}^{d}\right]-\left[N X_{p}\right]\left[\bar{\alpha}^{o}\right]+A N\right\}
\end{aligned}
$$

where $\mathrm{D}$ is the determinant associated with system (35)-(36). It can easily be shown to be positive. The parameters $\mathrm{A}$ and $\mathrm{B}$ are defined as follows

$$
A=\sum_{h} n^{h} \pi^{h} \frac{\partial \hat{x}}{\partial p}+\sum_{h} \rho^{h} x^{h}\left(x^{h}-\frac{X}{N}\right)
$$




$$
B=\sum_{h} \rho^{h}\left(x^{h}-\frac{X}{N}\right)
$$

The terms A and B play an important role in the interpretation of the results. To start with the latter, note that $\mathrm{B}$ describes the nature and the degree of heterogeneity in conditional demand between groups. If there is no demand heterogeneity (i.e., $x^{h}=\mathrm{X} / \mathrm{N}$ for all $\mathrm{h}$ ) then $\mathrm{B}=0$. Alternatively, $\mathrm{B}$ can be positive or negative depending on the nature of heterogeneity. If the ownership probabilities are generally less price sensitive for groups with above average conditional demands then $\mathrm{B}$ is positive. If on the contrary the entry probabilities of high demand groups are more price sensitive then B will be negative. The term A is a sum of Slutsky substitution terms and a heterogeneity term. However, it is shown in De Borger (2000) that it summarises a simple property of average consumption $\bar{x}=\mathrm{X} / \mathrm{N}$. More precisely, it turns out that

$$
\frac{\partial \bar{x}}{\partial p}=\frac{A}{N} .
$$

In other words, if a variable price increase has a stronger impact on ownership than on overall consumption so that average consumption declines, then $\mathrm{A}<0$. If the opposite holds, $\mathrm{A}>0$.

\subsection{Interpretation of the tax rules}


Turning to interpretation, we first focus on heterogeneity by assuming zero income effects and no distributive concerns. Specifically, assume $\frac{\partial x^{h}}{\partial y^{h}}=\frac{\partial \pi^{h}}{\partial y^{h}}=0$ and let private marginal social utilities be constant for all groups, i.e., $\beta^{h} \frac{\partial V_{1}^{h}}{\partial y^{h}}=m$ for all h, where $\mathrm{m}$ is the common marginal social utility of income. Simple algebra shows that these assumptions imply $\bar{\alpha}^{d}=\bar{\alpha}^{o}=\frac{m}{\lambda}$ and that, using the definition of $\mathrm{B},(37)$ and (38) reduce to

$$
\begin{aligned}
& p-c-\theta=\left(\frac{\lambda-m}{\lambda}\right) \frac{N}{D} B \\
& F=-\left(\frac{\lambda-m}{\lambda}\right) \frac{N}{D} A
\end{aligned}
$$

We focus on the case where at the optimum the shadow cost of public funds exceeds one. The signs of (p-c- $\theta$ ) and $\mathrm{F}$ are uniquely determined by the signs of $\mathrm{B}$ and $\mathrm{A}$, respectively. First consider the variable tax. Suppose, for example, that ownership probabilities are generally less price sensitive for low-demand than for high-demand groups (so that $\mathrm{B}<0$ ), then the variable tax will be below the full marginal external cost. Alternatively, the tax will exceed marginal external cost if participation by high demand groups is generally more price sensitive than for low demand groups $(B>0)^{16}$. The structure of the fixed fee $\mathrm{F}$ is independent of external cost concerns (although its level will of course depend on external costs). It may be positive or negative depending on the sign of the term A. As long as a variable price increase reduces average consumption levels $\mathrm{X} / \mathrm{N}$ we have $\mathrm{A}<0$, and therefore $\mathrm{F}>0$.

Turning to the role of distributional concerns, (37)-(38) clearly illustrate the importance of the distributional characteristics of ownership, of demand, and of the externality. First, note that the distributive characteristics of ownership and demand have 
opposite effects on the pricing structure. For a given distributional characteristic of ownership $\bar{\alpha}^{o}$ a lower variable tax and a higher fixed fee result if $\bar{\alpha}^{d}$ is large, i.e., if high demand groups are highly valued in the social welfare function. This makes sense because the benefit of the lower variable tax largely goes to high demanders. On the other hand, a higher distributional characteristic of ownership $\bar{\alpha}^{o}$ has the opposite effect: it reduces the fixed fee and raises the variable price. Again this makes sense, since the lower fixed fee benefits groups with high ownership probabilities.

Therefore, it matters for the price structure whether the government is more concerned about inequalities in the distribution of ownership or in conditional demand. Suppose for simplicity that all groups are of equal size, and that the policymaker assigns generally larger net social marginal utilities to poor groups. If the rich have much higher ownership probabilities but conditional demands between poor and rich do not differ much, then distributive policies are optimally implemented by emphasising a relatively low fixed fee. Alternatively, if ownership probabilities do not vary much but the rich have substantially larger conditional demands, then distributive concern suggests a fairly low variable tax.

Finally, turn to the distributional implications of the externality itself. Since from a qualitative viewpoint the distributive results do not strongly depend on the presence of feedback effects, we ignore feedbacks in the remainder of this section. To capture the concern with respect to the distribution of external costs over groups, note that in the absence of feedback effects the full marginal external cost can be rewritten as

$$
\theta=\left\{\sum_{h} \beta^{h} n^{h} m e c^{h}\right\}
$$

where $\quad m e c^{h}=-\frac{\partial f(X)}{\partial X} \frac{1}{\lambda}\left[\pi^{h} \frac{\partial V_{1}^{h}}{\partial E}+\left(1-\pi^{h}\right) \frac{\partial V_{2}^{h}}{\partial E}\right]$ 
is the direct marginal external cost imposed on an individual of group $h$. Then we can define the 'distributional characteristic of the externality' as follows:

$$
g=\frac{\sum_{h} \beta^{h} n^{h} m e c^{h}}{M E C}
$$

where $M E C=\sum_{h} n^{h} m e c^{h}$ is the unweighted total marginal cost. The distributional characteristic of the externality will be large if groups to which the government assigns a large welfare weight bear more of the external costs. Substitution of (42) in (41) then yields

$$
\theta=g M E C
$$

The role of the distribution of the externality for the optimal prices is then straightforward. Both higher total marginal cost and a higher distributional characteristic $\mathrm{g}$ raise the variable price, ceteris paribus. For example, if low-income groups bear most of the burden of the externality and the government wants redistribution towards these groups then the variable price rises. This is more than proportionately paid by high demanders. The fixed fee is correspondingly reduced to satisfy the budget restriction.

\subsection{Empirical implications}

For an example of the implications of the main findings in this section, let us return to the optimal taxation of cars. The most important parameters that determine the optimal fixed and variable components of the two-part tariff have clearly been identified, and it is perfectly possible to speculate on the sign of the most important parameters using available empirical estimates. First, with respect to the heterogeneity terms, there is empirical evidence (de Jong (1990), Train (1986)) that groups with high conditional 
demands are less price sensitive, and that variable price increases reduce the average demand for kilometres. Together these elements suggests that $\mathrm{B}>0$ and $\mathrm{A}<0$. In the absence of distributive concerns this would imply variable taxes exceeding marginal external cost and positive fixed fees, assuming, of course, that the budget constraint is sufficiently restrictive so that the shadow cost of funds exceeds marginal social utility of income. Second, to take account of distributive considerations, assume that the government assigns larger welfare weights to low-income groups. There is ample evidence that both ownership probabilities and conditional demands are positively correlated with income so that both distributive characteristics are likely to be fairly small (de Jong (1990)). More importantly, (34) suggests under these conditions that $\bar{\alpha}^{d}<\bar{\alpha}^{o}$. If inequality in conditional demands is substantial then (37)-(38) imply a higher variable tax and a lower fixed fee. Third, it is well known that the external costs associated with car traffic are substantial, which tends to raise the optimal variable tax. However, empirical evidence indicates that congestion is quantitatively the most important externality (Mayeres, Ochelen and Proost (1996)). Due to a higher valuation of time, it is reasonable to believe that the burden of time losses more than proportionately fall on high-income groups. This suggests that the distributive characteristic of external costs $\mathrm{g}$ is fairly small. If this is indeed true, it would tend to reduce the optimal variable $\operatorname{tax}$.

In sum, without detailed empirical work it is impossible to say what the optimal tax structure should look like. On the one hand, heterogeneity and distributive issues of ownership and demand point at high variable taxes, but on the other hand the small distributive characteristics of external costs points in the opposite direction. What is clear, though, is that current tax systems may need substantial adjustment to take into consideration recent findings on external transport costs. 


\section{Conclusions}

In this paper we presented a simple discrete choice model to study optimal two-part tariffs in the presence of externalities. The analysis was cast in terms of the optimal taxation of car ownership and car use to correct for external costs of car transport. Results can be summarised as follows. First, the model suggested that when perfect tax instruments are available the optimal variable taxes do not equal direct marginal external cost, unless the externality does not affect the car ownership probabilities. It was shown that if increases in externalities reduce ownership probabilities then the variable tax exceeds the direct marginal external cost. The implication is that the precise characteristics of the relevant externalities matter. Externalities such as congestion and accident risk are likely to have an effect on car ownership probabilities in the long-run. Pollution on the other probably affects consumer welfare but does not reduce car ownership. These externalities therefore receive a different treatment in the optimal variable tax rules. Since in practice both pollution and congestion matter then the deviation of the variable tax from the direct marginal external cost depends on the relative importance of the different types of externality.

Second, not surprisingly in a first-best environment the fixed taxes mainly depend on the severity of budgetary constraints and do not play an important role in correcting for external costs. However, when there are technical or political restrictions on tax instruments, the fixed tax structure does become crucial to respond to external cost differences between car types. If optimal variable user taxes for some 
reason cannot be implemented then we showed that car types that generate the lowest external costs per kilometre should not necessarily enjoy lower fixed taxes. The relative size of fixed taxes on cars with different pollution, noise and safety characteristics depends in a complex way on the relation between variable taxes and marginal external costs, and on various price sensitivities that determine the budgetary implications of tax adjustments. Alternatively, suppose that cars differ in external costs that are unrelated to fuel use (e.g., because of airbags, particulate filters, etc.) and that the government has the possibility to implement an optimal common variable tax for different car types. Then we showed that the cleanest technologies should always be subject to the lowest fixed tax. This suggests that, at least if it is administratively feasible, it is optimal to apply fixed tax reductions to cars incorporating externality-reducing technologies such as airbags, catalytic converters, direct injection, etc.

Third, it was shown that distributive considerations have a strong impact on the optimal pricing structure. The role of the distributive characteristics of ownership, of demand, and of the external cost itself was analysed. Large concern about ownership inequality raises the variable tax, concern about demand inequality lowers it. Both the overall level of the external cost and the distributive characteristic of the externality raise the optimal variable tax. 


\section{Acknowledgments.}

I am grateful to Ken Small, Frank Verboven and two anonymous referees for detailed written suggestions. Moreover, seminar participants at CORE (UCL) and the Universities of Antwerp and Münich provided many interesting comments.

\section{References.}

ACEA (various issues), Motor vehicle taxation in Europe (Association of European Automobile Manufacturers, Brussels).

Anderson, S.P., de Palma, A. and J. Thisse, 1993, Discrete choice theory of product differentiation (The MIT Press, Cambridge).

Arnott, R., de Palma, A. and R. Lindsay, 1993, A structural model of peak period congestion: A traffic bottleneck with elastic demand, American Economic Review 83, 161-179.

Ben-Akiva, M. and S. Lerman, 1985, Discrete choice analysis: Theory and applications (The MIT Press, Cambridge).

Bös, D., 1986, Public enterprise economics (North Holland, Amsterdam).

Bovenberg, L. and R. de Mooij, 1994, Do environmental taxes yield a double dividend ?, American Economic Review 84, 1085-1089.

Bovenberg, L. and R. van der Ploeg, 1994, Environmental policy, public finance and the labour market in a second best world, Journal of Public Economics 55, 349-390.

De Borger, B., Ochelen, S., Proost, S. and D. Swysen, 1997, Alternative transport pricing and regulation policies: a welfare analysis for Belgium, Transportation Research 2D, 177-198. 
De Borger, B., 1997, Optimal pricing of public final and intermediate goods in the presence of externalities, European Journal of Political Economy 13, 765-781.

De Borger, B., 2000, Optimal two-part tariffs in a model of discrete choice, Journal of Public Economics 76, 127-150.

de Jong, G., 1990, An indirect utility model of the demand for cars, European Economic Review 34, 971-985.

Diamond, P.A., 1975, A many-person Ramsey tax rule, Journal of Public Economics 4, 227-244.

Domencich, T. and D. Mc Fadden, 1975, Urban travel demand: A behavioral analysis (North-Holland, Amsterdam).

EEC Green Paper, 1996, Towards fair and efficient pricing in transport: policy options for internalising the external costs of transport in the European Union (Brussels).

EU White Paper, 1999, Options for charging users directly for transport infrastructure operating costs (Brussels).

Feldstein, M.S., 1972, Equity and efficiency in public sector pricing: the optimal twopart tariff, Quarterly Journal of Economics 86, 175-187.

Glaister, S. and D. Lewis, 1978, An integrated fares policy for transport in London, Journal of Public Economics 9, 341-355.

Glazer, A. and E. Niskanen, 1992, Parking fees and congestion, Regional Science and Urban Economics 22, 123-132.

Goulder, L.H., 1995, Environmental taxation and the "double dividend": A reader's guide, International Tax and Public Finance 2, 157-183 
Kraus, M., 1989, The welfare gains from pricing road congestion using automatic vehicle identification and on-vehicle meters, Journal of Urban Economics 25, 261281.

Laffont, J.-J. and J. Tirole, 1993, A theory of incentives in procurement and regulation (MIT Press, Cambridge).

Lave, C., 1994, The demand curve under road pricing and the problem of political feasibility, Transportation Research 28A, 83-91.

Littlechild, S.J., 1975, Two-part tariffs and consumption externalities, Bell Journal of Economics 6, 661-670.

Mayeres, I., Ochelen, S. and S. Proost, 1997, The marginal external costs of urban transport, Transportation Research 1D, 111-130.

Mayeres, I., and S. Proost, 1997, Optimal tax and investment rules for congestion types of externalities, Scandinavian Journal of Economics 99, 261-279.

Mayeres, I., 2000, The efficiency effects of transport policies in the presence of externalities and distortionary taxes, Journal of Transport Economics and Policy, forthcoming.

Mc Fadden, D., 1981, Econometric models of probabilistic choice, in: Manski, C. and D. McFadden, eds., Structural analysis of discrete data with econometric applications (MIT Press, Cambridge).

Munk, K. J., 1999, A double dividend after all?, Public Economics Working Paper DPS 99.18 (Catholic University Leuven, Leuven).

Ng, Y. and M. Weisser, 1974, Optimal pricing with a budget constraint: the case of the two-part tariff, Review of Economic Studies XLI, 37-45. 
Parry, I. and A. Bento, 1999, Revenue recycling and the welfare effects of road pricing, working paper 99-45 (Resources for the Future, Washington D.C.).

Proost, S. and D. Van Regemorter, 1995, The double dividend and the role of inequality aversion and macroeconomic regimes, International Tax and Public Finance 2, 207-219.

Sandmo, A., 1975, Optimal taxation in the presence of externalities, Swedish Journal of Economics 77, 86-98.

Schmalensee, R., 1981, Monopolistic two-part pricing arrangements, Bell Journal of Economics 8, 445-476.

Sharkey, W. and D. Sibley, 1993, Optimal nonlinear pricing with regulatory preferences over consumer type, Journal of Public Economics 50, 197-229.

Small, K., 1983, The incidence of congestion tolls on urban highways, Journal of Urban Economics 13, 90-111.

Small, K. and H.S. Rosen, 1981, Applied welfare economics with discrete choice models, Econometrica 49, 105-130.

Spence, A.M., 1980, Multi-product quantity-dependent prices and profitability, Review of Economic Studies XLVII, 821-841.

Train, K., 1986, Qualitative choice analysis: Theory, econometrics, and an application to automobile demand (MIT Press, Cambridge).

Verhoef, E., 1996, Economic efficiency and social feasibility in the regulation of road transport externalities (Tinbergen Institute Research Series). 


\section{$\underline{\text { Appendix } 1}$}

Consider the problem

$$
\underset{p, F}{\operatorname{Max}} \mu \ln \left\{\exp \left(\frac{V_{1}(p, y-F, E)}{\mu}\right)+\exp \left(\frac{V_{2}(y, E)}{\mu}\right)\right\}
$$

subject to $\pi[(p-c) x+F] \geq G$

where, without loss of generality, we have normalised $n=1$. Associating a Lagrange multiplier $\lambda$ with the budget restriction and assuming that the budget constraint is binding at the optimum, the first-order condition with respect to $\mathrm{p}$ can be written as

$$
\begin{aligned}
& -\pi x \frac{\partial V_{1}}{\partial y}+\lambda\left[(p-c)\left(\pi \frac{\partial x}{\partial p}+x \frac{\partial \pi}{\partial p}\right)+\pi x+F \frac{\partial \pi}{\partial p}\right] \\
& +\left\{\pi \frac{\partial V_{1}}{\partial E}+(1-\pi) \frac{\partial V_{2}}{\partial E}+\lambda\left[(p-c)\left(\pi \frac{\partial x}{\partial E}+x \frac{\partial \pi}{\partial E}\right)+F \frac{\partial \pi}{\partial E}\right]\right\} \frac{d E}{d p}=0
\end{aligned}
$$

where we have used Roy's identity and appropriately collected terms. Substituting (3) into this expression, dividing by $\lambda$ and using the definition of the feedback (see (5)) yields after some straightforward algebra 


$$
(p-c-\theta)\left(\pi \frac{\partial x}{\partial p}+x \frac{\partial \pi}{\partial p}\right)+F \frac{\partial \pi}{\partial p}=\frac{\pi x}{\lambda}\left(\frac{\partial V_{1}}{\partial y}-\lambda\right)
$$

where

$$
\theta=-\frac{\partial f(X)}{\partial X} \frac{1}{1-\eta} \frac{1}{\lambda}\left[\pi \frac{\partial V_{1}}{\partial E}+(1-\pi) \frac{\partial V_{2}}{\partial E}\right]-\frac{\partial f(X)}{\partial X} \frac{1}{1-\eta}\left[(p-c)\left(\pi \frac{\partial x}{\partial E}+x \frac{\partial \pi}{\partial E}\right)+F \frac{\partial \pi}{\partial E}\right]
$$

Completely analogous procedures are used to develop the first-order condition with respect to F. Appropriately using (4) yields after similar manipulations

$$
(p-c-\theta)\left(\pi \frac{\partial x}{\partial F}+x \frac{\partial \pi}{\partial F}\right)+F \frac{\partial \pi}{\partial F}=\frac{\pi}{\lambda}\left(\frac{\partial V_{1}}{\partial y}-\lambda\right)
$$

Different solution procedures are possible to solve system (A1.1-A1.2). For example, multiply the second equation by $\mathrm{x}$ and subtract it from the first to obtain

$$
(p-c-\theta)\left(\pi \frac{\partial x}{\partial p}+x \frac{\partial \pi}{\partial p}-\pi x \frac{\partial x}{\partial F}-x^{2} \frac{\partial \pi}{\partial F}\right)+F\left(\frac{\partial \pi}{\partial p}-x \frac{\partial \pi}{\partial F}\right)=0
$$

Now note that differentiation of the probability (1) with respect to $\mathrm{p}$ and $\mathrm{F}$ implies $\frac{\partial \pi}{\partial p}=x \frac{\partial \pi}{\partial F}$. Moreover, the term $\left(\frac{\partial x}{\partial p}-x \frac{\partial x}{\partial F}\right)$ is the Slutsky compensated price effect of conditional demand which, with the exception of Leontief preferences, will be nonzero (i.e., negative). This then immediately yields

$$
p-c-\theta=0
$$

Finally, substituting this result in (A1.2), and noting that differentiation of (1) yields

$$
\frac{\partial \pi}{\partial F}=-\pi(1-\pi) \frac{\partial V_{1}}{\partial y}
$$


immediately implies

$$
F=-\left(\frac{m_{1}-\lambda}{\lambda}\right)\left(\frac{1}{(1-\pi) m_{1}}\right),
$$

where $m_{1}$ is shorthand notation for $\frac{\partial V_{1}}{\partial y}$.

\section{$\underline{\text { Appendix } 2}$}

The problem can be formulated as

$$
\begin{aligned}
& \underset{p_{1}, p_{2}, F_{1}, F_{2}}{\operatorname{Max}} \mu \ln \left\{\exp \left(\frac{V_{1}\left(p_{1}, y-F_{1}, E\right)}{\mu}\right)+\exp \left(\frac{V_{2}\left(p_{2}, y-F_{2}, E\right)}{\mu}\right)+\exp \left(\frac{V_{3}(y, E)}{\mu}\right)\right\} \\
& \text { subject to }\left\{\left[\left(p_{1}-c_{1}\right) x_{1}+F_{1}\right] \pi_{1}+\left[\left(p_{2}-c_{2}\right) x_{2}+F_{2}\right] \pi_{2}\right\} \geq G
\end{aligned}
$$

The procedure is similar to that described in Appendix 1, but marginal external costs and feedback effects are slightly adjusted to account for multiple car types. Take the first-order condition with respect to $p_{1}$ as an example. Using Roy's identity and collecting terms it can be written as

$$
\begin{aligned}
& -\pi_{1} x_{1} \frac{\partial V_{1}}{\partial y}+\lambda\left[\left(p_{1}-c_{1}\right)\left(\pi_{1} \frac{\partial x_{1}}{\partial p_{1}}+x_{1} \frac{\partial \pi_{1}}{\partial p_{1}}\right)+\pi_{1} x_{1}+F_{1} \frac{\partial \pi_{1}}{\partial p_{1}}+\left(p_{2}-c_{2}\right)\left(x_{2} \frac{\partial \pi_{2}}{\partial p_{1}}\right)+F_{2} \frac{\partial \pi_{2}}{\partial p_{1}}\right] \\
& +\left\{\pi_{1} \frac{\partial V_{1}}{\partial E}+\pi_{2} \frac{\partial V_{2}}{\partial E}+\left(1-\pi_{1}-\pi_{2}\right) \frac{\partial V_{3}}{\partial E}+\lambda\left[\left(p_{1}-c_{1}\right)\left(\pi_{1} \frac{\partial x_{1}}{\partial E}+x_{1} \frac{\partial \pi_{1}}{\partial E}\right)+F_{1} \frac{\partial \pi_{1}}{\partial E}+\left(p_{2}-c_{2}\right)\left(\pi_{2} \frac{\partial x_{2}}{\partial E}+x_{2} \frac{\partial \pi_{2}}{\partial E}\right)+F_{2} \frac{\partial \pi_{2}}{\partial E}\right]\right\} \frac{d E}{d p_{1}}=0
\end{aligned}
$$

Totally differentiating $E=f\left(X_{1}, X_{2}\right)$, we easily show

$$
\frac{d E}{d p_{1}}=\frac{\frac{\partial f\left(X_{1}, X_{2}\right)}{\partial X_{1}}\left(\pi_{1} \frac{\partial x_{1}}{\partial p_{1}}+x_{1} \frac{\partial \pi_{1}}{\partial p_{1}}\right)+\frac{\partial f\left(X_{1}, X_{2}\right)}{\partial X_{2}}\left(x_{2} \frac{\partial \pi_{2}}{\partial p_{1}}\right)}{1-\eta}
$$

where $\eta=\frac{\partial f\left(X_{1}, X_{2}\right)}{\partial X_{1}}\left(\pi_{1} \frac{\partial x_{1}}{\partial E}+x_{1} \frac{\partial \pi_{1}}{\partial E}\right)+\frac{\partial f\left(X_{1}, X_{2}\right)}{\partial X_{2}}\left(\pi_{2} \frac{\partial x_{2}}{\partial E}+x_{2} \frac{\partial \pi_{2}}{\partial E}\right)$ 
is the feedback effect. Substituting this expression in the first-order condition and manipulating the result yields

$\left(p_{1}-c_{1}-\theta_{1}\right)\left(\pi_{1} \frac{\partial x_{1}}{\partial p_{1}}+x_{1} \frac{\partial \pi_{1}}{\partial p_{1}}\right)+\left(p_{2}-c_{2}-\theta_{2}\right)\left(x_{2} \frac{\partial \pi_{2}}{\partial p_{1}}\right)+F_{1} \frac{\partial \pi_{1}}{\partial p_{1}}+F_{2} \frac{\partial \pi_{2}}{\partial p_{1}}=\frac{\pi_{1} x_{1}}{\lambda}\left(\frac{\partial V_{1}}{\partial y}-\lambda\right)$

where the $\theta_{i}$ are the full marginal external costs associated with $X_{i}$. They are defined as

$$
\begin{aligned}
\theta_{i}=-\frac{\partial f\left(X_{1}, X_{2}\right)}{\partial X_{i}} \frac{1}{1-\eta} \frac{1}{\lambda}\left[\pi_{1} \frac{\partial V_{1}}{\partial E}+\pi_{2} \frac{\partial V_{2}}{\partial E}+\left(1-\pi_{1}-\pi_{2}\right) \frac{\partial V_{3}}{\partial E}\right] \\
-\frac{\partial f\left(X_{1}, X_{2}\right)}{\partial X_{i}} \frac{1}{1-\eta}\left[\left(p_{1}-c_{1}\right)\left(\pi_{1} \frac{\partial x_{1}}{\partial E}+x_{1} \frac{\partial \pi_{1}}{\partial E}\right)+F_{1} \frac{\partial \pi_{1}}{\partial E}+\left(p_{2}-c_{2}\right)\left(\pi_{2} \frac{\partial x_{2}}{\partial E}+x_{2} \frac{\partial \pi_{2}}{\partial E}\right)+F_{2} \frac{\partial \pi_{2}}{\partial E}\right]
\end{aligned}
$$

A completely analogous procedure can be used with respect to $p_{2}$. For the fixed taxes, only slight adjustments are needed. For example, for $F_{1}$ it suffices to note that

$$
\frac{d E}{d F_{1}}=\frac{\frac{\partial f\left(X_{1}, X_{2}\right)}{\partial X_{1}}\left(\pi_{1} \frac{\partial x_{1}}{\partial F_{1}}+x_{1} \frac{\partial \pi_{1}}{\partial F_{1}}\right)+\frac{\partial f\left(X_{1}, X_{2}\right)}{\partial X_{2}}\left(x_{2} \frac{\partial \pi_{2}}{\partial F_{1}}\right)}{1-\eta}
$$

and to use this result in the appropriate first-order condition.

Summarising the four first-order conditions, we obtain the system

$$
\begin{aligned}
& \left(p_{1}-c_{1}-\theta_{1}\right)\left(\pi_{1} \frac{\partial x_{1}}{\partial p_{1}}+x_{1} \frac{\partial \pi_{1}}{\partial p_{1}}\right)+\left(p_{2}-c_{2}-\theta_{2}\right)\left(x_{2} \frac{\partial \pi_{2}}{\partial p_{1}}\right)+F_{1} \frac{\partial \pi_{1}}{\partial p_{1}}+F_{2} \frac{\partial \pi_{2}}{\partial p_{1}}=\frac{\pi_{1} x_{1}}{\lambda}\left(\frac{\partial V_{1}}{\partial y}-\lambda\right) \\
& \left(p_{1}-c_{1}-\theta_{1}\right)\left(x_{1} \frac{\partial \pi_{1}}{\partial p_{2}}\right)+\left(p_{2}-c_{2}-\theta_{2}\right)\left(x_{2} \frac{\partial \pi_{2}}{\partial p_{2}}+\pi_{2} \frac{\partial x_{2}}{\partial p_{2}}\right)+F_{1} \frac{\partial \pi_{1}}{\partial p_{2}}+F_{2} \frac{\partial \pi_{2}}{\partial p_{2}}=\frac{\pi_{2} x_{2}}{\lambda}\left(\frac{\partial V_{2}}{\partial y}-\lambda\right) \\
& \left(p_{1}-c_{1}-\theta_{1}\right)\left(\pi_{1} \frac{\partial x_{1}}{\partial F_{1}}+x_{1} \frac{\partial \pi_{1}}{\partial F_{1}}\right)+\left(p_{2}-c_{2}-\theta_{2}\right)\left(x_{2} \frac{\partial \pi_{2}}{\partial F_{1}}\right)+F_{1} \frac{\partial \pi_{1}}{\partial F_{1}}+F_{2} \frac{\partial \pi_{2}}{\partial F_{1}}=\frac{\pi_{1}}{\lambda}\left(\frac{\partial V_{1}}{\partial y}-\lambda\right) \\
& \left(p_{1}-c_{1}-\theta_{1}\right)\left(x_{1} \frac{\partial \pi_{1}}{\partial F_{2}}\right)+\left(p_{2}-c_{2}-\theta_{2}\right)\left(\pi_{2} \frac{\partial x_{2}}{\partial F_{2}}+x_{2} \frac{\partial \pi_{2}}{\partial F_{2}}\right)+F_{1} \frac{\partial \pi_{1}}{\partial F_{2}}+F_{2} \frac{\partial \pi_{2}}{\partial F_{2}}=\frac{\pi_{2}}{\lambda}\left(\frac{\partial V_{2}}{\partial y}-\lambda\right)
\end{aligned}
$$

The solution procedure is similar to that in Appendix 1 as well. For example, multiply the third equation by $x_{1}$ and subtract it from the first. Noting that the logit 
probabilities imply $\frac{\partial \pi_{1}}{\partial p_{1}}=x_{1} \frac{\partial \pi_{1}}{\partial F_{1}}$ and $\frac{\partial \pi_{2}}{\partial p_{1}}=x_{1} \frac{\partial \pi_{2}}{\partial F_{1}}$, and assuming nonzero Slutsky substitution effects this immediately implies $p_{1}-c_{1}-\theta_{1}=0$. Following the same reasoning for the second and fourth equation leads to $p_{2}-c_{2}-\theta_{2}=0$. Finally, substituting the optimal variable taxes and solving for the fixed taxes yields the solution reported in the paper.

\section{$\underline{\text { Appendix } 3}$}

The problem is to

$$
\begin{aligned}
& \underset{F_{1}, F_{2}}{\operatorname{Max}} \mu \ln \left\{\exp \left(\frac{V_{1}\left(p_{1}, y-F_{1}, E\right)}{\mu}\right)+\exp \left(\frac{V_{2}\left(p_{2}, y-F_{2}, E\right)}{\mu}\right)+\exp \left(\frac{V_{3}(y, E)}{\mu}\right)\right\} \\
& \text { subject to }\left\{\left[\left(p_{1}-c_{1}\right) x_{1}+F_{1}\right] \pi_{1}+\left[\left(p_{2}-c_{2}\right) x_{2}+F_{2}\right] \pi_{2}\right\} \geq G
\end{aligned}
$$

where the $p_{i}$ are exogenous. The first-order conditions can be written as

$$
\begin{aligned}
& F_{1} \frac{\partial \pi_{1}}{\partial F_{1}}+F_{2} \frac{\partial \pi_{2}}{\partial F_{1}}=\frac{\pi_{1}}{\lambda}\left(\frac{\partial V_{1}}{\partial y}-\lambda\right)-\left(p_{1}-c_{1}-\theta_{1}\right)\left(\pi_{1} \frac{\partial x_{1}}{\partial F_{1}}+x_{1} \frac{\partial \pi_{1}}{\partial F_{1}}\right)-\left(p_{2}-c_{2}-\theta_{2}\right)\left(x_{2} \frac{\partial \pi_{2}}{\partial F_{1}}\right) \\
& F_{1} \frac{\partial \pi_{1}}{\partial F_{2}}+F_{2} \frac{\partial \pi_{2}}{\partial F_{2}}=\frac{\pi_{2}}{\lambda}\left(\frac{\partial V_{2}}{\partial y}-\lambda\right)-\left(p_{1}-c_{1}-\theta_{1}\right)\left(x_{1} \frac{\partial \pi_{1}}{\partial F_{2}}\right)-\left(p_{2}-c_{2}-\theta_{2}\right)\left(\pi_{2} \frac{\partial x_{2}}{\partial F_{2}}+x_{2} \frac{\partial \pi_{2}}{\partial F_{2}}\right)
\end{aligned}
$$

Writing this system in matrix notation, we solve using Cramer's rule. Using the definitions of the various probabilities (see (17)) yields after some algebra

$$
F_{1}=\frac{-\left(\frac{m-\lambda}{\lambda}\right)+\left(p_{1}-c_{1}-\theta_{1}\right)\left[\left(1-\pi_{2}\right) \frac{\partial x_{1}}{\partial F_{1}}-x_{1} m\left(1-\pi_{1}-\pi_{2}\right)\right]+\left(p_{2}-c_{2}-\theta_{2}\right)\left(\pi_{2} \frac{\partial x_{2}}{\partial F_{2}}\right)}{m\left(1-\pi_{1}-\pi_{2}\right)}
$$




$$
F_{2}=\frac{-\left(\frac{m-\lambda}{\lambda}\right)+\left(p_{1}-c_{1}-\theta_{1}\right)\left(\pi_{1} \frac{\partial x_{1}}{\partial F_{1}}\right)+\left(p_{2}-c_{2}-\theta_{2}\right)\left[\left(1-\pi_{1}\right) \frac{\partial x_{2}}{\partial F_{2}}-x_{2} m\left(1-\pi_{1}-\pi_{2}\right)\right]}{m\left(1-\pi_{1}-\pi_{2}\right)}
$$

where we have assumed for simplicity that the marginal utilities of income are independent of the choice of car type, i.e., $m_{1}=m_{2}=m$.

\section{$\underline{\text { Appendix } 4}$}

The problem is

$$
\begin{aligned}
& \underset{p, F_{1}, F_{2}}{\operatorname{Max}} \mu \ln \left\{\exp \left(\frac{V_{1}\left(p, y-F_{1}, E\right)}{\mu}\right)+\exp \left(\frac{V_{2}\left(p, y-F_{2}, E\right)}{\mu}\right)+\exp \left(\frac{V_{3}(y, E)}{\mu}\right)\right\} \\
& \text { subject to }\left\{\left[\left(p-c_{1}\right) x_{1}+F_{1}\right] \pi_{1}+\left[\left(p-c_{2}\right) x_{2}+F_{2}\right] \pi_{2}\right\} \geq G
\end{aligned}
$$

The first order condition for $\mathrm{p}$ can be written as

$$
\begin{aligned}
& -\pi_{1} x_{1} \frac{\partial V_{1}}{\partial y}-\pi_{2} x_{2} \frac{\partial V_{2}}{\partial y}+ \\
& \lambda\left[\left(p-c_{1}\right)\left(\pi_{1} \frac{\partial x_{1}}{\partial p}+x_{1} \frac{\partial \pi_{1}}{\partial p}\right)+\pi_{1} x_{1}+\pi_{2} x_{2}+F_{1} \frac{\partial \pi_{1}}{\partial p}+\left(p-c_{2}\right)\left(x_{2} \frac{\partial \pi_{2}}{\partial p}+\pi_{2} \frac{\partial x_{2}}{\partial p}\right)+F_{2} \frac{\partial \pi_{2}}{\partial p}\right] \\
& +\left\{\pi_{1} \frac{\partial V_{1}}{\partial E}+\pi_{2} \frac{\partial V_{2}}{\partial E}+\left(1-\pi_{1}-\pi_{2}\right) \frac{\partial V_{3}}{\partial E}+\lambda\left[\left(p-c_{1}\right)\left(\pi_{1} \frac{\partial x_{1}}{\partial E}+x_{1} \frac{\partial \pi_{1}}{\partial E}\right)+F_{1} \frac{\partial \pi_{1}}{\partial E}+\left(p-c_{2}\right)\left(\pi_{2} \frac{\partial x_{2}}{\partial E}+x_{2} \frac{\partial \pi_{2}}{\partial E}\right)+F_{2} \frac{\partial \pi_{2}}{\partial E}\right]\right] \frac{d E}{d p}=0
\end{aligned}
$$

We follow analogous procedures as before. First note that we now have

$$
\frac{d E}{d p}=\frac{\frac{\partial f\left(X_{1}, X_{2}\right)}{\partial X_{1}}\left(\pi_{1} \frac{\partial x_{1}}{\partial p}+x_{1} \frac{\partial \pi_{1}}{\partial p}\right)+\frac{\partial f\left(X_{1}, X_{2}\right)}{\partial X_{2}}\left(x_{2} \frac{\partial \pi_{2}}{\partial p}+\pi_{2} \frac{\partial x_{2}}{\partial p}\right)}{1-\eta}
$$

where the feedback is as before (see Appendix 2). Substituting this result and defining the $\theta_{i}$ identically as before we obtain 


$$
\begin{aligned}
& \left(p-c_{1}-\theta_{1}\right)\left(\pi_{1} \frac{\partial x_{1}}{\partial p}+x_{1} \frac{\partial \pi_{1}}{\partial p}\right)+\left(p-c_{2}-\theta_{2}\right)\left(x_{2} \frac{\partial \pi_{2}}{\partial p}\right)+F_{1} \frac{\partial \pi_{1}}{\partial p}+F_{2} \frac{\partial \pi_{2}}{\partial p} \\
& =\frac{\pi_{1} x_{1}}{\lambda}\left(\frac{\partial V_{1}}{\partial y}-\lambda\right)+\frac{\pi_{2} x_{2}}{\lambda}\left(\frac{\partial V_{2}}{\partial y}-\lambda\right)
\end{aligned}
$$

The first-order conditions for the fixed taxes are the same as in Appendix 3, but substituting $p_{1}=p_{2}=p$. This implies

$$
\begin{gathered}
\left(p-c_{1}-\theta_{1}\right)\left(\pi_{1} \frac{\partial x_{1}}{\partial F_{1}}+x_{1} \frac{\partial \pi_{1}}{\partial F_{1}}\right)+\left(p-c_{2}-\theta_{2}\right)\left(x_{2} \frac{\partial \pi_{2}}{\partial F_{1}}\right)+F_{1} \frac{\partial \pi_{1}}{\partial F_{1}}+F_{2} \frac{\partial \pi_{2}}{\partial F_{1}}=\frac{\pi_{1}}{\lambda}\left(\frac{\partial V_{1}}{\partial y}-\lambda\right) \\
\left(p-c_{1}-\theta_{1}\right)\left(x_{1} \frac{\partial \pi_{1}}{\partial F_{2}}\right)+\left(p-c_{2}-\theta_{2}\right)\left(\pi_{2} \frac{\partial x_{2}}{\partial F_{2}}+x_{2} \frac{\partial \pi_{2}}{\partial F_{2}}\right)+F_{1} \frac{\partial \pi_{1}}{\partial F_{2}}+F_{2} \frac{\partial \pi_{2}}{\partial F_{2}}=\frac{\pi_{2}}{\lambda}\left(\frac{\partial V_{2}}{\partial y}-\lambda\right)
\end{gathered}
$$

Writing the system consisting of A4.1, A4.2 en A4.3 in matrix notation, solving by Cramer's rule, and manipulating the results yields the solution reported in the paper.

\section{$\underline{\text { Appendix } 5}$}

The first-order condition for this problem with respect to $\mathrm{p}$ can be written, after collecting terms, as

$$
\begin{aligned}
& \sum_{h} \beta^{h} n^{h} \pi^{h} \frac{\partial V_{1}^{h}}{\partial p}+ \\
& \lambda\left\{(p-c)\left[\sum_{h} n^{h}\left(\pi^{h} \frac{\partial x^{h}}{\partial p}+x^{h} \frac{\partial \pi^{h}}{\partial p}\right)\right]+\sum_{h} n^{h} \pi^{h} x^{h}+F\left(\sum_{h} n^{h} \frac{\partial \pi^{h}}{\partial p}\right)\right\} \\
& +\left\{\sum n^{h} \beta^{h}\left[\pi^{h} \frac{\partial V_{1}^{h}}{\partial E}+\left(1-\pi^{h}\right) \frac{\partial V_{2}^{h}}{\partial E}\right]+\lambda\left[\sum_{h} n^{h}\left[(p-c) x^{h}+F\right] \frac{\partial \pi^{h}}{\partial E}+\sum_{h} n^{h} \pi^{h}(p-c) \frac{\partial x^{h}}{\partial E}\right]\right\} \frac{d E}{d p}=0
\end{aligned}
$$


where $\frac{d E}{d p}$ is, as before, the full impact of a price change on the level of the externality. Using the relations $\mathrm{E}=\mathrm{f}(\mathrm{X})$ and $X=\sum_{h} n^{h} \pi^{h} x^{h}$ it is now easily shown that

$$
\frac{d E}{d p}=\frac{\frac{\partial f(.)}{\partial X}\left[\sum_{h} n^{h}\left(\pi^{h} \frac{\partial x^{h}}{\partial p}+x^{h} \frac{\partial \pi^{h}}{\partial p}\right)\right]}{1-\eta}
$$

where $\eta=\frac{\partial f(.)}{\partial X}\left[\sum_{h} n^{h}\left(\pi^{h} \frac{\partial x^{h}}{\partial E}+x^{h} \frac{\partial \pi^{h}}{\partial E}\right)\right]$ is the feedback effect of the externality, appropriately redefined. Substitution of this expression in the first-order condition yields, after rearrangement and collecting terms

$$
\begin{aligned}
& \sum_{h} \beta^{h} n^{h} \pi^{h} \frac{\partial V_{1}^{h}}{\partial p}+ \\
& \lambda\left\{(p-c-\theta)\left[\sum_{h} n^{h}\left(\pi^{h} \frac{\partial x^{h}}{\partial p}+x^{h} \frac{\partial \pi^{h}}{\partial p}\right)\right]+\sum_{h} n^{h} \pi^{h} x^{h}+F\left(\sum_{h} n^{h} \frac{\partial \pi^{h}}{\partial p}\right)\right\}=0 .
\end{aligned}
$$

where

$$
\begin{aligned}
\theta=-\frac{\partial f(.)}{\partial X} \frac{1}{1-\eta} \frac{1}{\lambda}\left\{\sum_{h} \beta^{h} n^{h}\left[\pi^{h} \frac{\partial V_{1}^{h}(.)}{\partial E}+\left(1-\pi^{h}\right) \frac{\partial V_{2}^{h}}{\partial E}\right]\right\} \\
-\frac{\partial f(.)}{\partial X} \frac{1}{1-\eta}\left\{(p-c)\left[\sum_{h} n^{h}\left(\pi^{h} \frac{\partial x^{h}}{\partial E}+x^{h} \frac{\partial \pi^{h}}{\partial E}\right)\right]+F\left(\sum_{h} n^{h} \frac{\partial \pi^{h}}{\partial E}\right)\right\}
\end{aligned}
$$

is the full marginal external cost associated with a small increase in $\mathrm{X}$.

To focus on distributive effects it will be instructive, following the procedure in De Borger (2000), to decompose price effects into substitution and income effects. Define compensated price effects of conditional demands by the Slutsky equation $\frac{\partial x^{h}}{\partial p}=\frac{\hat{x}^{h}}{\partial p}-\frac{\partial x^{h}}{\partial y^{h}} x^{h}$, where $\hat{x}^{h}$ is compensated demand. Similarly, follow Small and Rosen (1981) in defining compensated price effects of the probability functions $\pi^{h}$ by $\frac{\partial \pi^{h}}{\partial p}=\frac{\partial \hat{\pi}^{h}}{\partial p}-\frac{\partial \pi^{h}}{\partial y^{h}} x^{h}$, where the $\hat{\pi}^{h}$ are the compensated choice probabilities. 
Substituting these expressions in (A.5.1), using Roy's identity, dividing all terms by $\lambda$ and slightly rearranging finally yields expression (32) in the paper.

The procedure for the first-order condition with respect to $\mathrm{F}$ is completely analogous. It is given by

$$
\begin{aligned}
& \sum_{h} \beta^{h} n^{h} \pi^{h} \frac{\partial V_{1}^{h}}{\partial F}+\sum_{h} \beta^{h} n^{h} \pi^{h} \frac{\partial V_{1}^{h}}{\partial E} \frac{d E}{d F}+\sum_{h} \beta^{h} n^{h}\left(1-\pi^{h}\right) \frac{\partial V_{2}^{h}}{\partial E} \frac{d E}{d F} \\
&+\lambda\left\{(p-c)\left[\sum_{h} n^{h}\left(\pi^{h} \frac{\partial x^{h}}{\partial F}+x^{h} \frac{\partial \pi^{h}}{\partial F}\right)\right]+\sum_{h} n^{h} \pi^{h}+F\left(\sum_{h} n^{h} \frac{\partial \pi^{h}}{\partial F}\right)\right\} \\
&+\lambda\left\{\left[\sum_{h} n^{h}(p-c)\left(\pi^{h} \frac{\partial x^{h}}{\partial E}+x^{h} \frac{\partial \pi^{h}}{\partial E}\right)\right]+F\left(\sum_{h} n^{h} \frac{\partial \pi^{h}}{\partial E}\right)\right\} \frac{d E}{d F}=0 .
\end{aligned}
$$

To rewrite this expression first note that $\frac{\partial V_{1}^{h}}{\partial F}=-\frac{\partial V_{1}^{h}}{\partial y^{h}}$ and $\frac{\partial x^{h}}{\partial F}=-\frac{\partial x^{h}}{\partial y^{h}}$. Second, differentiate the logit probabilities with respect to $\mathrm{p}$ and $\mathrm{F}$ to find $\frac{\partial \pi^{h}}{\partial F}=\frac{1}{x^{h}} \frac{\partial \pi^{h}}{\partial p}$. Third, using $\mathrm{E}=\mathrm{f}(\mathrm{X})$ and differentiating yields

$$
\frac{d E}{d F}=\frac{\frac{\partial f(.)}{\partial X}\left[\sum_{h} n^{h}\left(\pi^{h} \frac{\partial x^{h}}{\partial F}+x^{h} \frac{\partial \pi^{h}}{\partial F}\right)\right]}{1-\eta}
$$

Finally, using these expressions together with the above decompositions in substitution and income effects and the definitions of $\theta$ and the $\alpha^{h}$ 's allows the condition for $\mathrm{F}$ to be written as in the text (see (33)). 


\section{Endnotes}

${ }^{1}$ Policy documents emphasising the need for pricing reforms include, for example, the EEC Green Paper (1996) on efficient pricing and the recent White Paper (1999) on transport infrastructure charging.

${ }^{2}$ Apart from studies specifically dealing with the transport sector there is of course a large theoretical literature on optimal taxation in the presence of externalities. Relevant papers include, among others, Sandmo (1975), Bovenberg and van der Ploeg (1994), Bovenberg and de Mooij (1994), Goulder (1995), Proost and Van Regenmortel (1995) and Munk (1999).

${ }^{3}$ Specifically, they distinguish between committed and supplementary consumption.

${ }^{4}$ De Borger (2000, Appendix C) shows how to generalise the analysis to other discrete choice models in the absence of externalities. Similar procedures could be used in the case of externalities.

${ }^{5}$ An alternative approach would be to incorporate government revenues, weighted by an exogenous shadow cost of funds, as part of the objective function. This leads to similar optimal tax rules. The main difference between the two approaches is the assumption with respect to the cost of public funds.

${ }^{6}$ In the econometric literature the $\mu_{i}$ are often interpreted as stochastic components due to, e.g., unobservable taste differences across consumers (see, e.g., Anderson et al (1993), Domencich and McFadden (1975)) on the possible interpretations of the error term). As pointed out by a referee, the interpretation of the additive 'stochastic' term as reflecting taste heterogeneity, without reference to possible econometric interpretations, is more in line with the welfare economic analysis of this paper. ${ }^{7}$ It is obvious that ownership of a car involves fixed annual capital and depreciation costs, but incorporating this annual cost does not affect any of the optimal pricing results to be derived below. It is therefore ignored in the problem formulation.

${ }^{8}$ Note that this setup implies that indifference curves intersect the $\mathrm{X}$-axis. We therefore assume (also

see De Jongh (1990)) that $\lim _{p \rightarrow \infty} V_{1}(p, y-F, E)=U(0, y, E)$

${ }^{9}$ A non-binding constraint would correspond to the case where unconstrained welfare maximisation yields revenues exceeding the required minimum. Alternatively, it corresponds to the case where at the optimum the shadow cost of public funds is zero.

${ }^{10}$ Intuitively, the reason is that the feedback in conditional demand has two opposing welfare effects. On the one hand, it dampens the direct welfare effect of the externality by reducing demand. On the other hand, by lowering demand it reduces tax revenues. One easily shows that in the case of the conditional demands these two welfare effects precisely cancel out in the optimal pricing rule.

${ }^{11}$ However, note that, with some adjustments, the model could also be reformulated to describe optimal pricing of private car transport versus public transport services.

${ }^{12}$ Importantly, note that the focus of this section is on the role of fixed and variable taxes to reflect differences in external costs between cars. We do not analyse the alternative problem of how variable taxes should be adjusted for a given car type to cope with differences in external costs in time (e.g. between peak and off-peak periods) and space (e.g., in an urban or interurban environment). The model could easily be adjusted to cover these cases as well. However, since fixed taxes do not allow differentiation in time and space they have no explicit role in solving this problem. Optimal variable taxation under these circumstances has been studied in detail elsewhere (see, e.g., Arnott et al. (1993), De Borger et al. (1997), Verhoef (1996)).

${ }^{13}$ Given the setup it might have been preferable to consider a nested logit structure where in a first stage consumers decide on ownership, and at a second stage they decide on car type. This slightly complicates the analysis, but does not yield additional insights.

${ }^{14}$ One also easily shows (see (25)) that, under strong ceteris paribus conditions, an exogenous increase in $\theta_{1}$ raises the tax difference $F_{1}-F_{2}$, an increase in $\theta_{2}$ reduces it.

${ }^{15}$ Finally, note that under ceteris paribus conditions one easily shows that increases in an arbitrary $\theta_{i}$ raises the variable price $\mathrm{p}$. Moreover, an increase in $\theta_{1}$ (respectively $\theta_{2}$ ) raises (reduces) the tax difference $F_{1}-F_{2}$.

${ }^{16}$ Note that these results can be considered as externality-corrected 'multidimensional' generalisations of results on two-part tariffs in, e.g., Ng and Weisser (1974), Schmalensee (1981), and Laffont and Tirole (1993). 